\title{
Uremic Solutes Produced by Colon Microbes
}

\author{
Hisae Tanaka ${ }^{a}$ Tammy L. Sirich ${ }^{b}$ Timothy W. Meyer ${ }^{b}$ \\ ${ }^{a}$ Health Evaluation and Promotion Center, Tokai University Hospital, Isehara, Kanagawa, Japan; ${ }^{\mathrm{b}}$ The Departments of \\ Medicine, VA Palo Alto HCS and Stanford University, Palo Alto, CA, USA
}

\section{Key Words \\ Uremia $\cdot$ Microbiome $\cdot$ Colon}

\begin{abstract}
Background: Colon microbes produce a large number of organic compounds that are foreign to mammalian cell metabolism. Summary: Some of the compounds made by microbes are absorbed in the colon and then normally excreted by the kidneys. Accumulation of these compounds in the plasma as uremic solutes may contribute to illness in patients whose kidneys have failed. Mass spectrometry is expanding our knowledge of the chemical identity of the colon-derived uremic solutes, and DNA sequencing technologies are providing new knowledge of the microbes and metabolic pathways by which they are made. Because they are made in an isolated compartment by microbes, their production may prove simpler to suppress than the production of other uremic solutes. Key Messages: To the extent that they are toxic, suppressing their production could improve the health of renal failure patients without the need for more intensive or prolonged dialysis.

(c) 2015 S. Karger AG, Basel
\end{abstract}

\section{The Colon Microbiome}

The human gut harbors over 100 trillion microbes that comprise a symbiotic ecosystem $[1,2]$. This colon 'microbiome' performs multiple functions which have not been fully elucidated. Its most important function through evolutionary history has probably been to degrade plant polysaccharides that cannot be digested in the small intestine, providing energy to the human host in the form of short chain fatty acids. While this process provides only a small portion of the energy used daily in humans consuming an 'industrialized' diet, it can be a crucial source of energy when the diet contains more unprocessed plant foods [3]. Colon microbes also produce micronutrients including some vitamins and can produce hormones that promote fat storage. In addition, the colon microbiome limits colonization of the gut by pathogens and stimulates the human immune system in useful ways.

\section{Uremic Solutes Produced by Colon Microbes}

In addition to its beneficial products, the colon microbiome produces a large number of solutes that have no biologic value. Many of these solutes are absorbed through the colon epithelium and then normally excreted by the kidneys, often after conjugation. The colon-derived solutes that have been most extensively investigated are indoxyl sulfate and p-cresol sulfate, which are formed as depicted in figure 1 . These compounds have received the most attention because they are formed in relatively large quantities. They were therefore detected in human urine by the methods of classic organic chemistry and then shown to accumulate in the plasma when the kidneys fail.

\section{KARGER 125}

(c) 2015 S. Karger AG, Base

0253-5068/15/0404-0306\$39.50/0

E-Mail karger@karger.com

www.karger.com/bpu
Timothy W. Meyer

Nephrology 111R, Palo Alto VAHCS

3801 Miranda Ave. Palo Alto, CA 94303 (USA)

E-Mail twmeyer@stanford.edu 


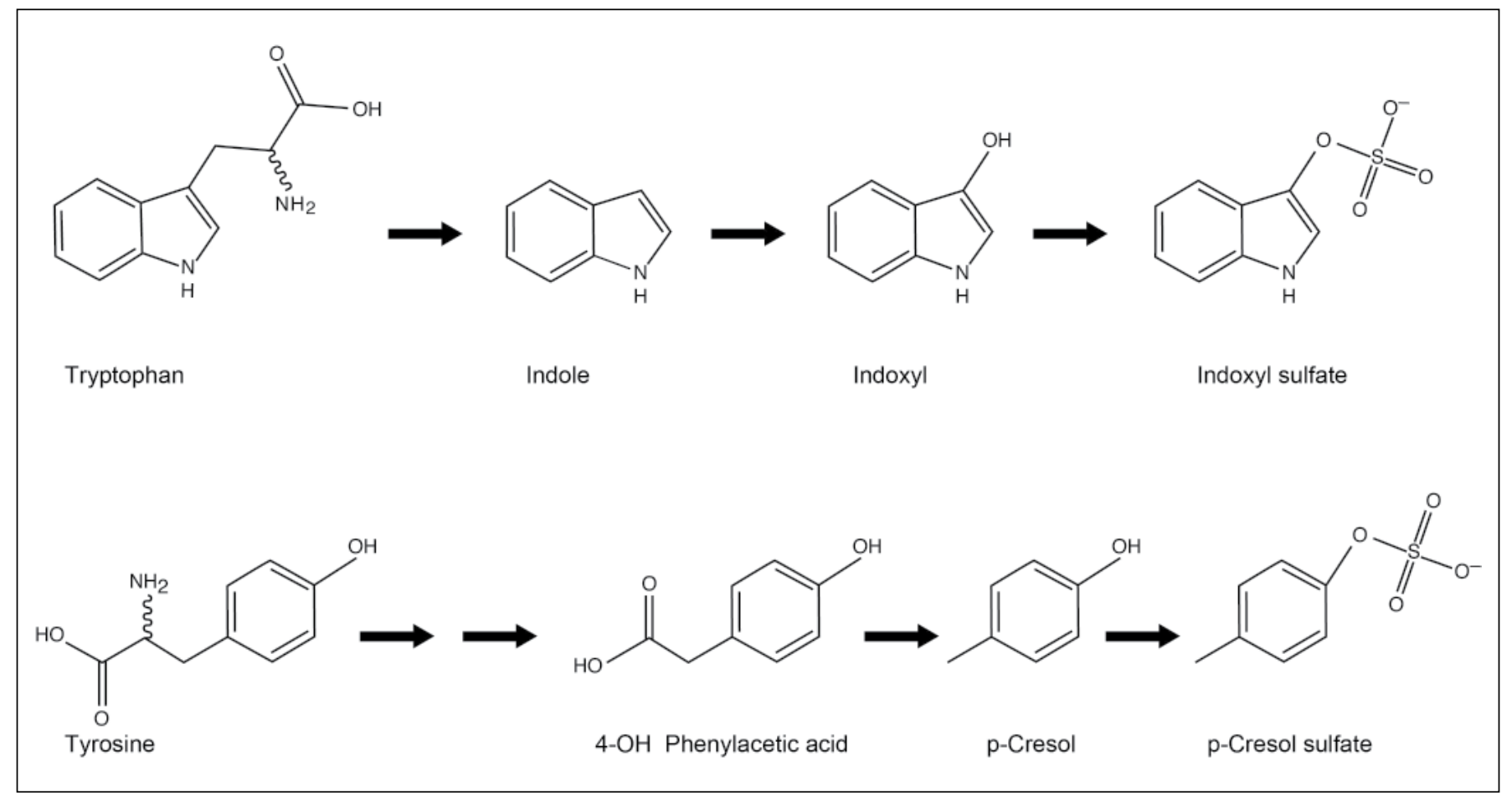

Fig. 1. Microbial generation of indoxyl sulfate from tryptophan and of p-cresol sulfate from tyrosine. Tryptophan is converted to indole by tryptophanase, which is found only in microbes. Absorption of indole in the colon is then followed by oxidation and sulfation in the liver. Tyrosine is converted by microbes in two steps to 4-hydroxy phenylacetic acid, which is then decarboxylated to p-cresol by an enzyme which has been shown to be present most

As described below, there is considerable though not conclusive evidence that they are toxic.

Mass spectrometry has made it possible to identify many more uremic solutes and to determine which of these are made by colon microbes. Kikuchi et al. [4] first used mass spectrometry to detect solutes that accumulate in the plasma of rats with renal insufficiency. Sato et al. [5] subsequently demonstrated the capacity of mass spectrometry to detect compounds which accumulate in the plasma of hemodialysis patients. Lists of known uremic solutes have been prepared by combining mass spectrometric findings with results obtained using other analytic methods [6-9]. We recently identified an additional 48 uremic solutes by comparing plasma samples from hemodialysis patients and normal subjects using an established metabolomic platform [10]. Combination of these solutes with those identified in previous reports yielded a list of more than 270 known uremic solutes.

Solutes produced by colon microbes can be identified by combining mass spectrometry with maneuvers that notably in Clostridium difficile. Sulfation of p-cresol is then accomplished in the colonic epithelium and possibly also in the liver. Older reports measured p-cresol rather than p-cresol sulfate in the plasma of dialysis patients because assay techniques employed acidification which hydrolyzed the conjugate. Lesser portions of both indoxyl and p-cresol are conjugated with glucuronic acid rather than sulfuric acid. suppress microbial solute production. A pioneering study by Wikoff et al. [11] identified solutes produced by gut microbes by comparing plasma from germ-free rats and conventional animals. Of note, some solutes shown to be of microbial origin were later found to accumulate in the plasma of mice lacking the anion transporter OAT1, suggesting that they are removed from the body largely by renal tubular secretion [12]. Kikuchi et al. [13] subsequently identified solutes whose plasma levels were reduced by the administration of the oral sorbent AST-120 in rats with renal insufficiency. Aronov et al. [14] initially identified colon-derived uremic solutes by comparing plasma solute profiles in dialysis patients with and without colons. We recently identified six additional colon-derived solutes by reanalyzing the samples collected by Aronov et al. [14], using an established metabolomic platform [10]. Interestingly, these compounds were all phenyl and indole compounds. Query of the BioCyc database identified potential microbial sources for these colon-derived solutes. Com- 
Table 1. Colon-derived uremic solutes

\begin{tabular}{ll}
\hline Solute & References \\
\hline Indoxyl sulfate & {$[11,13,14]$} \\
Indoxyl glucuronide & {$[14]$} \\
5-Hydroxyindole & {$[14]$} \\
3-Indolepropionic acid & {$[11,14]$} \\
p-Cresol sulfate & {$[11,13,14]$} \\
p-Cresol glucuronide & {$[43]$} \\
Phenol sulphate & {$[11,13]$} \\
Phenol glucuronide & {$[14]$} \\
Alpha-N-phenylacetyl-L-glutamine & {$[14]$} \\
Phenylpropionylglycine & {$[11]$} \\
Cinnamoylglycine & {$[11,14]$} \\
4-Ethylphenyl sulfate & {$[13]$} \\
Hippuric acid & {$[11,13,14]$} \\
Phenylacetic acid & {$[10]$} \\
2-Aminophenol sulphate & {$[10]$} \\
3-Hydroxyhippuric acid & {$[10]$} \\
2-Methoxyphenol sulfate & {$[10]$} \\
4-Methylcatechol sulfate & {$[10]$} \\
3-(3-(Sulfooxy)phenyl) propanoic acid & {$[10]$} \\
Trymethylamine N-oxide & {$[24,25]$} \\
\hline
\end{tabular}

These compounds accumulate in the plasma in renal failure, and evidence in the references suggests that they are derived from colon microbial metabolism.

bining the results of these reports yields a total of 20 colon-derived uremic solutes as listed in table 1 . This list will undoubtedly get longer as more mass spectrometric studies are performed.

\section{The Toxicity of Colon-Derived Uremic Solutes}

Evidence has accumulated that the best known colonderived uremic solutes, $\mathrm{p}$-cresol sulfate and indoxyl sulfate, are toxic [15-21]. Recent studies have concentrated on the possibility that these compounds cause vascular injury. High levels of p-cresol sulfate have been correlated with cardiovascular diseases and mortality in patients with chronic kidney disease (CKD) $[18,19]$. Indoxyl sulfate has been shown to induce endothelial dysfunction via an induction of oxidative stress in vitro [20] and high serum levels have been associated with cardiovascular disease and mortality in CKD [21]. The structural relation of the uremic indoles and phenols to neurotransmitters has also encouraged speculation that they impair cognitive function, and it has recently been noted that they could do this by interfering with cleaning of the brain interstitium by the blood-brain barrier.
Another colon-derived solute, trimethylamine N-oxide (TMAO), has recently attracted considerable attention as a risk factor for cardiovascular disease [22]. TMAO is not made from amino acids but rather from choline, which is in turn derived largely from dietary meat. Initial studies associated high TMAO levels with increased risk of cardiovascular events in people who did not have renal failure $[23,24]$. Some studies have since associated high TMAO levels with cardiovascular disease in patients with renal failure, but this has not been a uniform finding $[25$, 26].

\section{The Colon Microbiome May Be Altered in CKD}

Just as mass spectrometry has increased our knowledge of uremic solutes, DNA sequencing technology has greatly increased our knowledge of the diversity and function of the colon microbes [27]. Application of this technology has recently revealed qualitative and quantitative changes in the gut microbiome in CKD [28]. Vaziri et al. [29] first assessed the taxonomy of the colon microbiome in hemodialysis patients using the Affymetrix Phylochip. Significant differences were found in the prevalence of a number of specific bacterial types. Because the study was conducted with an early version of the Phylochip it was not possible to assess microbial diversity. However a companion study using a later chip identified reduced diversity of the colon microbiome in rats with renal insufficiency.

Several factors could be responsible for alteration of the colon microbiome in patients with renal insufficiency. The first, particularly among patients with end-stage renal disease, is alteration of the diet. End-stage renal disease patients also frequently receive antibiotics and have prolonged colon transit time. In addition, the colon microbiome is itself exposed to increased concentrations of various compounds that accumulate in renal failure and can be metabolized by microbes. The most prominent of these is urea, which is converted to ammonia by microbial urease $[30,31]$. Other examples are creatinine, uric acid, and oxalate which enter the colon in increased quantities in renal failure and are degraded by microbes [3234].

Alterations in the microbiome in CKD have implications for future therapy, as described below. But much more needs to be learned about the microbiome before we can manipulate it to suppress solute production. Remarkably, microbial populations with divergent taxonomic profiles can have similar functional capacity as 
reflected by the presence of genes encoding enzymes for various metabolic pathways [35]. Functional capacity as well as taxonomy must therefore be assessed to gauge the extent to which disease alters the microbiome and to identify microbial processes that may be over or under represented in disease sufferers. One method of assessing functional capacity is to predict the genetic makeup of the microbiome based on the results of $16 \mathrm{~S}$ rRNA gene profiling and the genetic makeup of microbial species for which whole genome sequences have been reported. This approach, which limits cost, provided a remarkably accurate overall picture of microbial genes in samples from the Human Microbiome Project [36]. It has limited ability, however, to assess the prevalence of unusual microbial genes which are expressed irregularly in closely related species. The prevalence of such genes can be more reliably assessed by 'shotgun' sequencing of the microbial DNA present in fecal samples, although compared to the 16S rRNA-based metagenomic inference method this has the disadvantage of missing genes from low abundance species [37, 38]. Further studies with both of these complementary methods will therefore be needed to assess the prevalence in the microbiome of genes encoding enzymes responsible for the production of important uremic solutes.

\section{Reducing the Production of Colon-Derived Uremic Solutes}

Treatment of renal failure is currently focused on removing solutes by dialysis and largely ignores the alternate strategy of suppressing solute production. Maneuvers to suppress production, however, could prove particularly effective for solutes that are made in an isolated body compartment by microbes. Plasma levels of these solutes vary widely among patients with the same degree of renal insufficiency, further suggesting that solute production is variable and should be susceptible to manipulation. One potential means to limit the production of colon-derived solutes is to alter the food supplied to colon microbes. On an 'industrialized' diet, the colon microbes receive up to $10 \mathrm{~g}$ of amino acids in the form of incompletely digested proteins, sloughed intestinal cells, and secretions. The quantity of amino acids delivered to the colon may be increased in renal failure due to impaired digestion of proteins in the small intestine. These amino acids are the source of p-cresol sulfate, indoxyl sulfate, and some other uremic solutes produced by colon microbes.

Colon-Derived Uremic Solutes
Dietary protein restriction can limit delivery of amino acids to the colon but may have adverse effects and, if severe, result in negative nitrogen balance. An alternate means to reduce the microbial production of waste solutes from amino acids is to increase fiber intake. The term fiber includes carbohydrates and related compounds that escape digestion in the small intestine. With high-fiber intake these compounds provide energy for microbial growth. Amino acids reaching the colon are then used for synthesis of microbial proteins rather than being converted into waste solutes. Recent studies have shown that increasing fiber intake can reduce the plasma concentrations of p-cresol sulfate and indoxyl sulfate in hemodialysis patients $[39,40]$. Other studies have shown that among people with normal kidney function, those consuming a vegetarian diet which is high in fiber produce less p-cresol sulfate and indoxyl sulfate than those consuming an unrestricted diet [41].

The studies cited above show the increasing fiber intake can reduce production of $\mathrm{p}$-cresol sulfate and indoxyl sulfate, which are made from the amino acids tryptophan and phenylalanine/tyrosine, respectively. Not all the colon-derived uremic solutes are made from amino acids, however. We have recently found that many colonderived solutes are derived rather from polyphenols and related compounds in plant foods [10]. Plants contain thousands of such compounds with an extraordinary variety of structures. Many of them escape digestion in the small intestine and are metabolized by colon microbes. Several grams per day of dietary polyphenols are thereby transformed into new substances which are normally excreted by the kidney, often after conjugation in the liver. At present we do not know whether any of these substances are toxic. And consideration of the health effects of plant polyphenols has been focused largely on their potential benefit with particular attention to their potential antioxidant and anticarcinogenic activities. Accumulation of metabolites which are normally excreted by the kidney, however, could turn these putative benefits to harm in patients with renal failure.

Another potential means to reduce the burden of colon-derived solutes is to administer sorbents that bind their precursor compounds in the colon. The carbonbased sorbent AST-120 reduces plasma levels of indoxyl sulfate and can also reduce levels of p-cresol sulfate and other solutes [42]. Further work is required to determine whether use of sorbents can provide long-term health benefits in patients with renal failure.

Perhaps the most promising potential means to reduce microbial production of toxic solutes is to modify the 
composition of the microbiome. Limited studies have so far attempted to alter the microbiome by administration of 'probiotic' bacterial strains which do not produce toxins. A major problem is survival in the microbiome of the probiotic bacteria. Knowledge of the genetic makeup of the microbiome may ultimately provide more effective means to adjust its composition. Hopefully, it will be possible to introduce microbes in which the capacity to produce toxins has been genetically deleted but which are otherwise well fitted for survival in the colon microbial ecosystem.

\section{Increasing the Removal of Colon-Derived Solutes}

The alternative to suppressing solute production is to improve solute removal by dialysis. Indoxyl sulfate and p-cresol sulfate, the two best known colon-derived solutes, are more than $90 \%$ bound to plasma albumin. Because only the portions of bound solutes are available for diffusion through the dialysis membrane, their clearances are only a small fraction of the urea clearance during conventional dialysis. The clearance of the bound solutes, however, can be greatly increased by increasing the dialysate flow and dialyzer size. The clearance of bound solutes can also be increased by combining high-volume ultrafiltration with hemodialysis and adding sorbents to the dialysate. Theoretically, sustained application of these techniques could reduce the plasma concentrations of bound solutes without increasing either the duration or frequency of dialysis. More extensive clinical studies are required to determine the extent to which this can be accomplished in practice.

\section{Conclusion}

Colon microbes produce numerous compounds which are normally excreted in the urine and accumulate in the plasma when the kidneys fail. While there is evidence that some of the colon-derived compounds are toxic, our knowledge of their toxicity is far from complete. Better knowledge of solute toxicity could lead to new means to reduce the levels of toxic solutes in renal failure patients. In particular, because the colon-derived solutes are made in an isolated compartment by microbes, it may prove simpler to reduce their levels by suppressing their production than by enhancing their removal.

\section{Acknowledgements}

Support was provided by the NIH of the US Government (R01 DK101674-01).

\section{Conflict of Interest}

The authors have no conflicts of interest to disclose.

\section{References}

1 Ramezani A, Raj DS: The gut microbiome, kidney disease, and targeted interventions. J Am Soc Nephrol 2014;25:657-670.

$\checkmark 2$ Bäckhed F, Ley RE, Sonnenburg JL, Peterson DA, Gordon JI: Host-bacterial mutualism in the human intestine. Science 2005;307:19151920.

3 Nordgaard I, Mortensen PB: Digestive processes in the human colon. Nutrition 1995;11: $37-45$.

4 Kikuchi K, Itoh Y, Tateoka R, Ezawa A, Murakami K, Niwa T: Metabolomic analysis of uremic toxins by liquid chromatography/ electrospray ionization-tandem mass spectrometry. J Chromatogr B Analyt Technol Biomed Life Sci 2010;878:1662-1668.

5 Sato E, Kohno M, Yamamoto M, Fujisawa T, Fujiwara K, Tanaka N: Metabolomic analysis of human plasma from haemodialysis patients. Eur J Clin Invest 2011;41:241-255.

-6 Vanholder R, De Smet R, Glorieux G, Argiles A, Baurmeister U, Brunet P, Clark W, Cohen G, De Deyn PP, Deppisch R, Descamps-
Latscha B, Henle T, Jorres A, Lemke HD, Massy ZA, Passlick-Deetjen J, Rodriguez M, Stegmayr B, Stenvinkel P, Tetta C, Wanner C, Zidek W: Review on uremic toxins: Classification, concentration, and interindividual variability. Kidney Int 2003;63:19341943.

7 Duranton F, Cohen G, De Smet R, Rodriguez M, Jankowski J, Vanholder R, Argiles A: Nor$\mathrm{mal}$ and pathologic concentrations of uremic toxins. J Am Soc Nephrol 2012;23:1258-1270.

$\$ 8$ Niwa T: Update of uremic toxin research by mass spectrometry. Mass Spectrom Rev 2011; 30:510-521.

-9 Itoh Y, Ezawa A, Kikuchi K, Tsuruta Y, Niwa $\mathrm{T}$ : Protein-bound uremic toxins in hemodialysis patients measured by liquid chromatography/tandem mass spectrometry and their effects on endothelial ros production. Anal Bioanal Chem 2012;403:1841-1850.

10 Tanaka H, Sirich TL, Plummer NS, Weaver DS, Meyer TW: An enlarged profile of uremic solutes. PLoS One 2015;10:e0135657.
11 Wikoff WR, Anfora AT, Liu J, Schultz PG, Lesley SA, Peters EC, Siuzdak G: Metabolomics analysis reveals large effects of gut microflora on mammalian blood metabolites. Proc Natl Acad Sci U S A 2009;106:36983703.

12 Wikoff WR, Nagle MA, Kouznetsova VL, Tsigelny IF, Nigam SK: Untargeted metabolomics identifies enterobiome metabolites and putative uremic toxins as substrates of organic anion transporter 1 (Oat1). J Proteome Res 2011;10:2842-2851.

13 Kikuchi K, Itoh Y, Tateoka R, Ezawa A, Murakami K, Niwa T: Metabolomic search for uremic toxins as indicators of the effect of an oral sorbent AST- 120 by liquid chromatography/tandem mass spectrometry. J Chromatogr B Analyt Technol Biomed Life Sci 2010;878:2997-3002.

-14 Aronov PA, Luo FJ, Plummer NS, Quan Z, Holmes S, Hostetter TH, Meyer TW: Colonic contribution to uremic solutes. J Am Soc Nephrol 2011;22:1769-1776. 
15 Lin CJ, Wu V, Wu PC, Wu CJ: Meta-analysis of the associations of p-cresyl sulfate (PCS) and indoxyl sulfate (IS) with cardiovascular events and all-cause mortality in patients with chronic renal failure. PLoS One 2015;10:e0132589.

16 Watanabe $\mathrm{H}$, Miyamoto Y, Otagiri M, Maruyama T: Update on the pharmacokinetics and redox properties of protein-bound uremic toxins. J Pharm Sci 2011;100:36823695.

17 Vanholder R, Schepers E, Pletinck A, Nagler EV, Glorieux G: The uremic toxicity of indoxyl sulfate and p-cresyl sulfate: A systematic review. J Am Soc Nephrol 2014;25:1897-1907.

18 Meijers BK, Bammens B, De Moor B, Verbeke K, Vanrenterghem Y, Evenepoel P: Free pcresol is associated with cardiovascular disease in hemodialysis patients. Kidney Int 2008;73:1174-1180.

$\checkmark 19$ Liabeuf S, Barreto DV, Barreto FC, Meert N, Glorieux G, Schepers E, Temmar M, Choukroun G, Vanholder R, Massy ZA: Free p-cresylsulphate is a predictor of mortality in patients at different stages of chronic kidney disease. Nephrol Dial Transplant 2010;25: 1183-1191.

20 Yu M, Kim YJ, Kang DH: Indoxyl sulfate-induced endothelial dysfunction in patients with chronic kidney disease via an induction of oxidative stress. Clin J Am Soc Nephrol 2011;6:30-39.

-21 Barreto FC, Barreto DV, Liabeuf S, Meert N, Glorieux G, Temmar M, Choukroun G, Vanholder R, Massy ZA: Serum indoxyl sulfate is associated with vascular disease and mortality in chronic kidney disease patients. Clin J Am Soc Nephrol 2009;4:1551-1558.

22 Tang WH, Hazen SL: The contributory role of gut microbiota in cardiovascular disease. J Clin Invest 2014;124:4204-4211.

23 Wang Z, Klipfell E, Bennett BJ, Koeth R, Levison $\mathrm{BS}$, Dugar B, Feldstein AE, Britt EB, Fu $\mathrm{X}$, Chung YM, Wu Y, Schauer P, Smith JD, Allayee H, Tang WH, DiDonato JA, Lusis AJ, Hazen SL: Gut flora metabolism of phosphatidylcholine promotes cardiovascular disease. Nature 2011;472:57-63.

-24 Tang WH, Wang Z, Levison BS, Koeth RA, Britt EB, Fu X, Wu Y, Hazen SL: Intestinal microbial metabolism of phosphatidylcholine and cardiovascular risk. N Engl J Med 2013; 368:1575-1584
25 Stubbs JR, House JA, Ocque AJ, Zhang S, Johnson C, Kimber C, Schmidt K, Gupta A, Wetmore JB, Nolin TD, Spertus JA, Yu AS: Serum trimethylamine-n-oxide is elevated in CKD and correlates with coronary atherosclerosis burden. J Am Soc Nephrol 2015 Epub ahead of print.

26 Kaysen GA, Johansen KL, Chertow GM, Dalrymple LS, Kornak J, Grimes B, Dwyer T, Chassy AW, Fiehn O: Associations of trimethylamine $\mathrm{N}$-oxide with nutritional and inflammatory biomarkers and cardiovascular outcomes in patients new to dialysis. J Ren Nutr 2015;25:351-356

27 Qin J, Li R, Raes J, Arumugam M, Burgdorf KS, Manichanh C, Nielsen T, Pons N, Levenez F, Yamada T, Mende DR, Li J, Xu J, Li S, Li D, Cao J, Wang B, Liang H, Zheng H, Xie Y, Tap J, Lepage P, Bertalan M, Batto JM, Hansen T, Le Paslier D, Linneberg A, Nielsen HB, Pelletier E, Renault P, Sicheritz-Ponten T, Turner K, Zhu H, Yu C, Li S, Jian M, Zhou Y, Li Y, Zhang X, Li S, Qin N, Yang H, Wang J, Brunak S, Dore J, Guarner F, Kristiansen K, Pedersen O, Parkhill J, Weissenbach J, Bork P, Ehrlich SD, Wang J: A human gut microbial gene catalogue established by metagenomic sequencing. Nature 2010;464:59-65.

28 Vaziri ND, Zhao YY, Pahl MV: Altered intestinal microbial flora and impaired epithelial barrier structure and function in CKD: the nature, mechanisms, consequences and potential treatment. Nephrol Dial Transplant 2015, Epub ahead of print.

29 Vaziri ND, Wong J, Pahl M, Piceno YM, Yuan J, DeSantis TZ, Ni Z, Nguyen TH, Andersen GL: Chronic kidney disease alters intestinal microbial flora. Kidney Int 2013;83:308-315.

30 Mitch WE: Effects of intestinal flora on nitrogen metabolism in patients with chronic renal failure. Am J Clin Nutr 1978;31:1594-1600.

31 Fuller MF, Reeds PJ: Nitrogen cycling in the gut. Annu Rev Nutr 1998;18:385-411.

32 Mitch WE, Collier VU, Walser M: Creatinine metabolism in chronic renal failure. Clin Sci (Lond) 1980;58:327-335.

33 Hatch M, Freel RW, Vaziri ND: Intestinal excretion of oxalate in chronic renal failure. J Am Soc Nephrol 1994;5:1339-1343.

34 Vaziri ND, Freel RW, Hatch M: Effect of chronic experimental renal insufficiency on urate metabolism. J Am Soc Nephrol 1995;6: 1313-1317.
5 Human Microbiome Project Consortium: Structure, function and diversity of the healthy human microbiome. Nature 2012; 486:207-214

36 Langille MG, Zaneveld J, Caporaso JG, McDonald D, Knights D, Reyes JA, Clemente JC, Burkepile DE, Vega Thurber RL, Knight R, Beiko RG, Huttenhower C: Predictive functional profiling of microbial communities using 16S rRNA marker gene sequences. Nat Biotechnol 2013;31:814-821.

37 Weinstock GM: Genomic approaches to studying the human microbiota. Nature 2012; 489:250-256.

38 Yatsunenko T, Rey FE, Manary MJ, Trehan I, Dominguez-Bello MG, Contreras $M$, Magris M, Hidalgo G, Baldassano RN, Anokhin AP, Heath AC, Warner B, Reeder J, Kuczynski J, Caporaso JG, Lozupone CA, Lauber C, Clemente JC, Knights D, Knight R, Gordon JI: Human gut microbiome viewed across age and geography. Nature 2012;486: 222-227.

-39 Meijers BK, De Preter V, Verbeke K, Vanrenterghem Y, Evenepoel P: P-Cresyl sulfate serum concentrations in haemodialysis patients are reduced by the prebiotic oligofructose-enriched inulin. Nephrol Dial Transplant 2010; 25:219-224.

40 Sirich TL, Plummer NS, Gardner CD, Hostetter TH, Meyer TW: Effect of increasing dietary fiber on plasma levels of colon-derived solutes in hemodialysis patients. Clin J Am Soc Nephrol 2014;9:1603-1610.

41 Patel KP, Luo FJ, Plummer NS, Hostetter TH, Meyer TW: The production of $\mathrm{p}$-cresol sulfate and indoxyl sulfate in vegetarians versus omnivores. Clin J Am Soc Nephrol 2012;7:982988.

42 Lee CT, Hsu CY, Tain YL, Ng HY, Cheng BC, Yang CC, Wu CH, Chiou TT, Lee YT, Liao SC: Effects of AST-120 on blood concentrations of protein-bound uremic toxins and biomarkers of cardiovascular risk in chronic dialysis patients. Blood Purif 2014; 37:76-83.

43 Lesaffer G, De Smet R, Belpaire FM, Van Vlem B, Van Hulle M, Cornelis R, Lameire N, Vanholder R: Urinary excretion of the uraemic toxin p-cresol in the rat: Contribution of glucuronidation to its metabolization. Nephrol Dial Transplant 2003;18:1299-1306. 